\title{
Preparation of Public Housing Energy Efficiency Publications \\ for the \\ Atlanta Housing Authority
}

\author{
Conducted by: \\ Center for Process Optimization \\ Georgia Tech \\ Economic Development Institute \\ Atlanta, Georgia \\ Sponsored By: \\ The Atlanta Housing Authority \\ under a grant from the \\ U.S. Department of Energy
}

August 1995

\section{MASTER}

DISTRIRUTION OF THE CCOUAENT IS UNLMTED 


\title{
Table of Contents
}

\author{
Page

1. Executive Summary

2. Project Statement of Work

2

3. Program Procedures and Accomplishments

4

4. Program Results

8

5. Recommendations and Conclusions

\section{Appendix}

Pamphlets Developed and Distributed at Atlanta Housing Authority

\section{DISCLAIMER}

\begin{abstract}
This report was prepared as an account of work sponsored by an agency of the United States Government. Neither the United States Government nor any agency thereof, nor any of their employees, makes any warranty, express or implied, or assumes any legal liability or responsibility for the accuracy, completeness, or usefulness of any information, apparatus, product, or process disclosed, or represents that its use would not infringe privately owned rights. Reference herein to any specific commercial product, process, or service by trade name, trademark, manufacturer, or otherwise does not necessarily constitute or imply its endorsement, recommendation, or favoring by the United States Government or any agency thereof. The views and opinions of authors expressed herein do not necessarily state or reflect those of the United States Government or any agency thereof.
\end{abstract}




\section{PROJECT STATEMENT of WORK}

Project tasks that were completed under this contract are as follows:

\subsection{Task 1: Secure and Review Existing Materials}

a. Inventory existing low cost and no cost energy conservation materials that are available from HUD, weatherization programs, utilities, state government, non-profit energy conservation organizations, and others. Select the most effective information contained in these materials for inclusion in a new document targeted at public housing residents.

b. Refine the information to accommodate the educational background and motivations of the targeted recipients. Presently, four target groups were identified for pamphlets directed at their specific needs and opportunities:

1) Residents whose apartments are individually metered (low-rise apartments).

2) High-rise apartment residents who are not directly (individually) metered.

3) Low-rise owners, supervisors, and maintenance staff.

4) Single-family detached units with the option to purchase the dwelling.

c. Determine the motivational factors to assure action as a result of being exposed to the information. For example, residents who receive utility bill supplements are motivated by dollar cost savings. Residents of high-rise apartments are not individually metered. They may be motivated by greater comfort or possible rent reductions (resultant of overall building utility savings which manifest in the rent). Thus, residents for these two types of apartments are motivated differently. Also, many people today are environmentally conscious, thus factors that indicate help for the environment are desirable.

d. Finalize the format of the pamphlets and develop an educational plan for facility supervisors/maintenance staff, tenant orientation leaders, and residents. Produce prototype pamphlets for evaluation. Coordinate this closely with Atlanta Housing Authority Director of Residence Incentives.

\subsection{Task 2: Revise and Test Market}

Produce a document that contains information expected to be effective in promoting energy efficiency among public housing residents. With support from the Housing Authority, test market this document with residents of public housing projects in the Atlanta area. 
The test market will include several locations of varying types of apartments including high-rises, individual (single detached units) or duplex units (single floor), and two or three level (low rise) apartment buildings. The testing will include utility bill tracking (compared to historical utility data and surveys to verify and quantify resident response and the impact on utility costs.

\subsection{Task 3: Final Document and Dissemination Strategy}

Based on results from the test marketing work of Task 2, revise and print a final document that can be used for broad dissemination among Public Housing Authorities (PHAs) in the Southeast. In partnership with the HUD Regional Office, develop a dissemination strategy that will effectively reach these PHAs.

Task 3 will include a final report which will document the efforts and results. It will include suggestions with input from the DOE, HUD \& AHA group for a strategy of disseminating the finalized documents to Public Housing Authorities region-wide. 


\section{PROGRAM PROCEDURES and ACCOMPLISHMENTS}

\subsection{Survey-Existing Utility Consumption Practices}

During the heating season, a physical (walk through) survey of eight neighborhoods (Palmer House, Wildwood Lake Homes, University Homes, Techwood Homes, Clark Howell, Perry Homes, Harris Apartments, and Barge Homes) was conducted. This survey included made inspecting the three basic housing types (low rise, high rise, and single family detached) in efforts to get a perspective of existing living practices. Although, the survey is not statistically significant, it did yield some insight to problems and opportunities.

Observations are as follows:

- It appears to be a common practice to supplement apartment heating and clothes drying with the stove top and oven. A fire fighter from the Fulton County Fire Department - Station 17 (Mr. Gerald Greene) was interviewed to learn if there were frequent calls for fires due to this practice. No data was made available, but he remembered several calls for stove related fires in public housing.

- Older highrises (usually occupied by elderly residents) show poor maintenance of central mechanical systems. Low rise apartments with district heat and hot water show better maintenance due to the use of contractors, but critical problems may be overlooked.

- Apartments regularly have windows ajar.

- Residents seem to be reluctant to call the maintenance department for broken windows, detached weather stripping, and even a failed heater. Comments from the residents for the hesitancy were highly varied.

- Apartments are maintained at a higher temperature than appropriate in the winter. Temperatures in the range of $85 \mathrm{~F}$ - $90 \mathrm{~F}$ are common.

- Leaking faucets and toilets are common.

- Single family detached housing seem to be the best maintained in terms of building envelope maintenance. However, more in-depth maintenance like pilot light and burner cleaning and tuning, heater filter changing, and leaking faucets are needed. 
- Apartments are lighted throughout the day and extensively at night.

- Televisions remain "on" for extensive periods.

\subsection{Survey Existing Printed Materials and Documents Available}

Existing printed materials were collected from local sources including; the local U. S. Department of Energy (DOE), the state energy office, the Atlanta Housing Authority (AHA) resident training program, the Marietta Housing Authority, Southface Energy Institute, the U.S. Department of Housing and Urban Development and in-house materials.

These materials were used as input to develop the draft pamphlets and as a basis for critique at the residents meeting. The initial evaluation concluded the existing materials were generally written in too high of a reading level skill for effectiveness. Also, based on the walk through survey, some critical needs (e.g. proper and safe use of the stove) were not adequately addressed.

\subsection{Prepare Draft Pamphlets for Test Marketing}

Draft pamphlets were developed from the input obtained above. Also, input was obtained from DOE and the Atlanta Housing Authority (Director Executive Assistant, Director of Resident Initiatives, Resident Services Coordinator, Central Maintenance Manager, Director of New Resident Training, the Utilities Analysts Director, and from an AHA staff engineer).

The team held a meeting with members of the resident associations to evaluate the proposed brochure and the implementation of an energy conservation program. The meeting was lively and highly productive with several excellent suggestions. These su ggestions included the following:

- Utilize a multi-color presentation in the brochure (Green and grey were the consensus colors).

- Some of the text and pictures present an unclear message. Suggestions were offered to simplify the message and to focus only on key items.

- Additional energy conservation recommendations were suggested for the brochure. 
- A multi-media promotion approach was suggested including:

- Making energy conservation a regular (AHA and resident association) meeting agenda item,

- Show videotapes on the subject,

- Develop peer encouragement by installing energy monitors in each public housing neighborhood to encourage resident conservation,

- Make energy conservation a topic item in the local grade school as is currently done on environmental topics,

- Institute a cash prize competition for children's posters on energy conservation and mount posters in the public housing neighborhoods,

- Since energy conservation and safety go together to some extent, make these items parallel in promotional efforts,

- Require residents to attend training sessions,

- Make special announcements during heavy utility use times (extreme cold/hot periods) to heighten energy awareness during these critical periods, and

- Issue excess utility consumption bills to residents soon after extreme weather to render quick feedback. Currently, excess utility ! -consumption bills are distributed about three months after the high use month.

Based on this input, the draft pamphlet was refined and finalized for distribution.

\subsection{Present \& Distribute Finalized Pamphlets}

Four different pamphlets were produced for four target readers as follows; low-rise apartment residents, highrise apartment residents, single family detached unit residents, and facility maintenance personnel. The pamphlets were distributed to the test population which included the facility maintenance personnel, Palmer House Highrise apartments, Clark Howell Homes, and Wildwood Homes. Because of the popularity of the pamphlets, the Utility Analyst distributed pamphlets widely - especially to residents who complained about excess consumption bills.

\subsection{Conduct a Utility Cost Impact Analysis and Produce a Final Project Report}

In efforts to quantify the results of the endeavor, the project has endeavored to determine if the distribution of the pamphlets has resulted in reductions of utility costs. Utility costs for the two winters prior to the distribution of the pamphlets (1992-93 and 1993-94) was compared to the utility costs of the past winter (1994-95). 
Because of the differences in heating degree days changes from one winter to another, a direct comparison is not possible. Changes in utility consumption must be normalized for severity of the heating seasons of the comparison.

Other factors must be taken into account. Most notably are other services provided to the residents (to promote conservation) impact results. Also, occupancy level and turnover of residents will impact results. 


\section{PROGRAM RESULTS}

Reviewing the utility billing data for the focus group (Palmer House Highrise apartments, Clark Howell Homes, and Wildwood Homes) indicate an overall winter 1994-95 reduction in consumption of 5.2 percent with that of the 1992-93 winter and 3.1 percent with that of the 1993-94 winter period (January - April). Figure 1 indicates the weather data for the subject three winters. This data shows that the three winters of focus were all more moderate than the 30 year winter average (used for design purposes). Normalizing the impact of the mild winters and including additional utility conservation programs implemented at Atlanta Housing Authority during the test period make the results of the pamphlet inconclusive. However, upon conducting a physical survey one can conclude that substantial improvements in resident living practices have been achieved.

This and other recent programs focusing on improved living practices has had a significant impact on Atlanta Housing Authority. Additional utility conservation projects include:

1) Atlanta housing authority has begun to conduct consultations with residents who incur utility costs significantly in excess $(\$ 25-\$ 50)$ of the standard subsidy.

Because of the problems identified with resident heating practices and drying clothes using the electric cooking range, training has been intensified on the energy costs and safety impacts of this and other energy intensive practices.

2) Increased effort to reduce response time to resident service (maintenance) requests via a computerized work order system was implemented by the maintenance department.

3) The maintenance department has integrated the utility cost impact into their management function for appliance/equipment maintenance, and selection/ replacement. Maintenance contractors are monitored more closely for utility cost savings opportunities.

4) The local electric utility is increasing services to public housing residents by:

a. Conducting in-house counseling,

b. Demonstrating appliance maintenance (e.g. refrigerator coil cleaning) and leaving the cleaning tools for the resident's use,

c. Installing wall switch and socket plate seals, and

d. Providing, at no cost, up to five screw-in compact fluorescent lamps.

8 
5) The housing authority has upgraded its new resident training center which is also provides refresher courses for existing residents. The center is professionally managed and continuously improved.

The real impact of the program will best be evaluated during periods of extreme cold. Prior and during these periods, management must promote efficient utility consumption practices to promote extra effort for efficient consumption practices. 

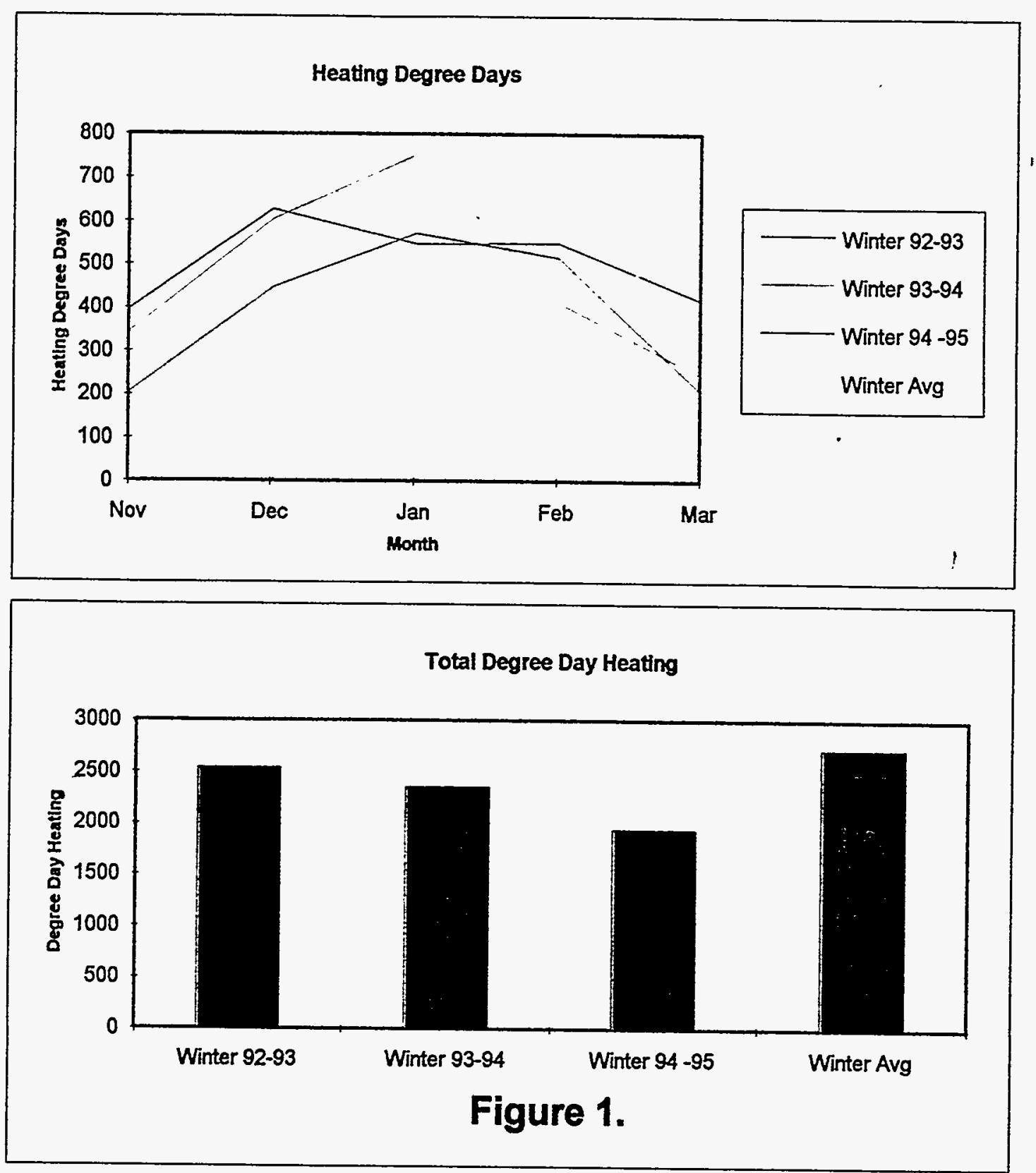


\section{RECOMMENDATIONS and CONCLUSIONS}

\subsection{Recommendations}

Disseminate pamphlets within housing authorities region wide:

Because a large number of housing authorities in this region have similar facility construction, the pamphlet should have a broad applicability in the southeast. Dissemination during new resident training programs and before the heating season will have a positive effect on utility consumption practices.

Implement a comprehensive energy conservation program in Atlanta Housing Authority (AHA) and reorganize the allocation of utility funds (and associated savings) so that this cost center shares with HUD in the savings achieved:

Some of the AHA savings are suggested to be allocated to improve maintenance operations and personnel training and other funds are suggested to be allocated for comprehensive resident training.

Atlanta Housing Authority (AHA), like most public housing organizations, operates a myriad of facility types, from single family dwellings and multi-family buildings, to very large high rise apartment buildings. Many of their facilities have large central systems for refuse waste, heating, hot water, utilities, utility metering etc. Also, like many institutional facility operators, the maintenance function is over worked, under staffed, under trained, and under budgeted. Thus, when a decision is made to replace a failed compact fluorescent lamp, for example, it may be replaced with the lower efficiency incandescent lamp because of the replacement cost is borne by the maintenance budget but the utility savings achieved (or lost) is not. Incurring a higher operating cost by installing lower cost and lower efficient equipment is perfectly rational bucause saving utility costs are not part of the maintenance department's economic function.

Universally, maintenance staffs do not take operating costs into account because they are evaluated primarily on facility system availability and secondly on working within their budget. However, because of the maintenance staff has intimate knowledge of facility operations, they have a tremendous potential to control utility costs in maintenance and operational practices.

The indicated problem is exacerbated when understaffed maintenance departments seek and receive budget allocations to contract some maintenance work to outsiders in efforts to augment existing maintenance operations. In this scenario, a third party 
contractor may have an even lower set (a subset of the maintenance department's) objectives or criteria to measure performance. For example, recently it was observed that a district hot water system was not functioning. To the casual observation, there were no problems. The natural gas fired hot water heaters had the pilot lights on and the water circulation pumps were operating. So, when the contractor performed his normal inspection of the boiler room, everything looked normal. In actuality, things were not normal, the control system would not turn the burners on, so only cold water circulated to the apartments. Why were the apartment residents not complaining? They had no economic function to motivate them. They simply opened the door on their electric ranges and heated their apartments by electrical resistance - causing the authority to pay three to four times the normal cost for heating. This single problem cost approximately $\$ 15,000$ per week until the problem was uncovered.

Knowing the realities indicated above, one might ask why haven't housing authority management and operators moved to a system where the maintenance. group is responsible for utility costs? We propose that they should. But, the perceived risk involved with the transition or of having the maintenance department manage such a large budget (larger than the maintenance budget) prevents this logical operating practice. Also, for the system to be effective, the maintenance department should have incentive (i.e. gain sharing) to manage the utility budget better than the current practice.

Public housing projects suffer from the same dilemma as many institutional (public and private) facilities. Utility cost control is managed as a separate cost center from maintenance operations. Installing energy efficient equipment frequently results in maintenance having to maintain more expensive energy systems with little or no budget improvement for the more complex energy efficient equipment and subsystems. Thus, maintenance does not share in the gain from installing energy efficient equipment, and in many cases, it is penalized. Maintenance functions are focused in other areas (e.g. occupant comfort) rather than optimal operation of energy efficient equipment. Because maintenance has a significant affect on facility energy efficiency both in the operations/maintenance of facility equipment and in the specification of replacement equipment and parts, a change in management and operational practice should be considered.

For public housing, when energy conservation measures are installed and a reduction in utility costs is realized, the allocation for paying utility bills from HUD is

- correspondingly reduced. Thus, public housing administration does not share in the gain (long term) of utility cost reduction, making the incentive to invest internal resources for instituting conservation programs less desirable. 
Institute a program where residents are financially rewarded for conservative usage practices:

Another major impact on public housing facility energy efficiency is the practices and habits of the building residents. The literature indicates that as much as 30 percent of public housing energy costs may be attributed to living habits. For example, some residents will regularly operate space heaters on a high output setting on cold days and moderate comfort by opening windows. Implementation of energy efficient equipment and systems results in sub-optimal savings if residents have not implemented living habits to complement energy efficient hardware improvements.

Currently, public housing residents have little incentive to be efficient at budgeting utility costs. They receive an allocation of utilities each month. So long as they do not exceed their allocation, they do not see any economic impact. Even when they do exceed their allocation, in many cases they still are not penalized. This is because many public housing units are not independently metered to properly distribute excess costs. A far better system would be to independently meter each apartment, and establish a fair utility allocation. If this allocation is exceeded, the resident should be penalized - much as it is done now, except on a no exceptions basis. However, by operating very conservatively, residents can frequently operate below their allocation. There is currently no incentive to do this. An excellent opportunity exists to prove the concept of rewarding the resident for being extra conservative. This can be accomplished if:

1) The resident is trained on improved living practices and

2) The resident is offered a financial incentive, i.e. share in the gains (i.e. savings).

As important, funds will be allocated to residents directly as a reward for energy efficient living habits. Thus, AHA management, residents, and maintenance operations share with HUD in the reward for excellence in utility cost savings. Also, residents learn an important lesson in developing conservative energy usage habits - an important aspect as they re-enter the privately owned living environment. Another compelling benefit, is AHA shares in the energy conservation gains thus it will have the necessary inducement to perpetuate energy efficiency improvements AND invest further in efficiency measures.

Institute a program to educate and enlist the support of public housing children:

Public housing residents have emphasized the strong influence their children have on parents. Today, the local schools are making a significant impact in environmental 
restoration/protection by creating awareness via class lessons and projects on this topic. Residents have encouraged us to institute a similar program for energy conservation and consumption awareness. A suggested program would involve training teachers, arranging packaged lessons and conducting contests (reports and posters). The contests would provide the pupil and the school tangible gain, motivating school participation and student focus. The product of the endeavor would be to further reinforce information about utility consumption practices in the public housing community via influence from children in the form of family interaction and peer involvement. School contest winners would display their work on housing authority bulletin boards and the community at large.

Produce a broader array of training delivery techniques for public housing residents:

Residents are bombarded with handout materials of all types. New materials that take ; advantage of multimedia technology is in order. Also, these materials, like the pamphlets developed within this program, need to focus on the intended target population. Most handout materials distributed are for a generic audience which does not address the uniqueness of the motivations and background of public housing residents.

Initiate a pilot gain sharing program:

The whole concept of subsidizing utilities should be re-evaluated. The utility subsidy appears to be ineffective in preparing residents for entering the world of self reliance. The present system may even hinder resident development by inhibiting an awareness of "cause and effect" - e.g. Use utilities excessively and experience little cost, or Conserve utilities and see no tangible gain/savings. A model system should be demonstrated that enables the resident to share savings with the public housing authority.

\subsection{Conclusions}

AHA has an excellent opportunity to demonstrate the validity of the concept of instituting comprehensive proven energy conservation techniques and advanced management techniques to indefinitely maintain a facility energy efficiency program vitality. It also has the opportunity to better prepare residents for energy efficient living upon leaving the public housing environment. 
With the state's utility demand side management program coming on line and several renovation projects imminent, a proper setting is in place to demonstrate state-of-theart energy conservation technologies and state-of-the-art facility maintenance practice. This demonstration can show not only highly efficient design execution but also effective energy management and efficient maintenance practices to perpetuate the savings indefinitely. Some of the suggested technologies for state of the art energy conservation technologies include:

Multi-unit Lowrise/Single Family units:

- High efficiency condensing furnaces,

- Spark ignition gas appliances,

- Efficient insulated building envelope systems,

- High efficiency heat pump heating/domestic water heating,

- Centralized hot water/heating systems,

- DDC controls and centralized energy management/control/metering,

- Complete relamp with efficient light sources,

- Energy efficient exterior lighting, and

- Heat pumps for space and hot water heating.

Highrise Apartment Buildings:

- High efficiency space heating boilers,

- DDC control with centralized energy management,

- Complete relamp with efficient light sources,

- Advanced insulated building envelope systems,

- High efficiency gas-fired central domestic water heating with smart temperature reset control,

- Heat pump district hot water systems,

- High efficiency CFC free central water chilling equipment,

- Variable-speed pumping equipment, and

- Outside air/exhaust air heat recovery. 
Improvements in facility maintenance management is proposed to include:

- Regimented training and evaluation program for job proficiency,

- Regimented training program for sustaining energy efficiency,

- Restructuring of utility budgeting, goal setting/evaluation, and cost control for maintenance department responsibility for reaching/maintaining efficiency goals,

-Establishment of a gain sharing program for the residents, the maintenance department, and management for utility savings, and

- Installation of an effective investment evaluation tool to enable maintenance to effectively evaluate maintenance costs, capital costs, operating costs, etc. for equipment maintenance and equipment replacement. 


\section{Appendix}

Pamphlets Developed and Distributed at Atlanta Housing Authority 
The need to conserve energy is a very 'eal concern. While not demonstrating the apid'escalations of the 1970s, energy costs ontinue to increase and will impact budget illocations without conscientious management ifforts. Energy management should be viewed is a method to reduce the energy budget and ree funds for other improvements.

Energy is an expensive commodity and hould be conserved at all times. The cost of refueling an automobile is easy to see so people don't leave their cars running while hey are away for long periods of time. However, electricity and natural gas costs are not quite as direct, so people leave their TV's and heaters on when they are away.

The way to solve this problem is to develop a new philosophy on energy use and conservation. It is a real money saver! The extra money can be reinvested in the upkeep and maintenance of the facility.

The following pages are filled with simple easy steps to save energy. All of these ideas represent minimal time and money conservation ideas that can present substantial payback.
Keep doors and windows closed while heating or cooling.

4. Close off unused areas by closing registers and window shades.

4atch windows and skylights at the end of the day.

Close blinds, drapes and skylight covers at the end of the day.

4 Check doors for proper and complete closure.

Check caulking and weatherstripping around doors and .. windows.
Turn off unneeded lights.

Keep fixtures, lamps and room surfaces clean.

Replace lighting covers, lenses, diffusers and globes that have yellowed.

Use natural light from windows and skylights.

$\checkmark$ Use proper replacement bulbs to avoid extra cost from over illumination. Use energy efficient lamps like compact fluorescents for replacement of burned out incandescent lamps. 
Ise Central Air Sanditioning Lificiently

Reduce fouling on the water-side of the evaporator.

Keep chilled-water temperature as high as possible and condenser water temperature as $\mathrm{j} w$ as possible.

Reduce use of "hot-ga: bypass".

Check compressor for proper capacity cont"??

Check chiller controls frequently for proper function and calibratio.

Clean and flush cooling tower basins semiannually.

4 Clean condenser coils annually.

Use Hot Water Heater Efficiently

4 Reduce hot water temperature to the minimum required.

Add additional insulation to hot water tank.

4 Maintain optimal air to fuel ratio in fossilfueled heaters.

4 Drain hot water tank periodically to remove sediment buildup.

Repair leaks in joints, faucets and valves.

Maintain vent damper on natural draft system.

Adjust timer on hot water circulating pump to occupied hours only.

Turn off water heaters and pilots when not in
Efficiently

Contract with a qualified specialist to perform tune-ups annually.

If facility has more than one boiler, operate as few possible.

Maintain proper chemical treatment to prevent scale buildup on the water side of the tubes.

At the end of the heating season, turn off the gas to avoid the expense of maintaining a pilot flame. 


\section{Maintain Building}

Envelope
Improve Lighting

Efficiency
Use Packaged

HVAC

Units Efficienthy
Keep doors and windows closed while heating or cooling.

4 Close off unused areas by closing registers and window shades.

4 Latch windows and skylights at the end of the day.

Close blinds, drapes and skylight covers at the end of the day.

Check doors for proper and complete closure.

Check caulking and weatherstripping around doors and

.- windows.
Turn off unneeded lights.

Keep fixtures, lamps and room surfaces clean.

Replace lighting covers, lenses, diffusers and globes that have yellowed.

Use natural light from windows and skylights.

$\checkmark$ Use proper replacement bulbs to avoid extra cost from over illumination.

$\checkmark$ Use energy efficient lamps like compact fluorescents for replacement of burned out incandescent lamps. urn off the unit when unneeded or when rooms are unoccupied.

4aintain proper refrigerant charge in units.

:educe air leakage through unit panels and exposed ductwork.

: lean air filters and replace old ones.

idjust drive belts to proper tension to avoid slippage. 


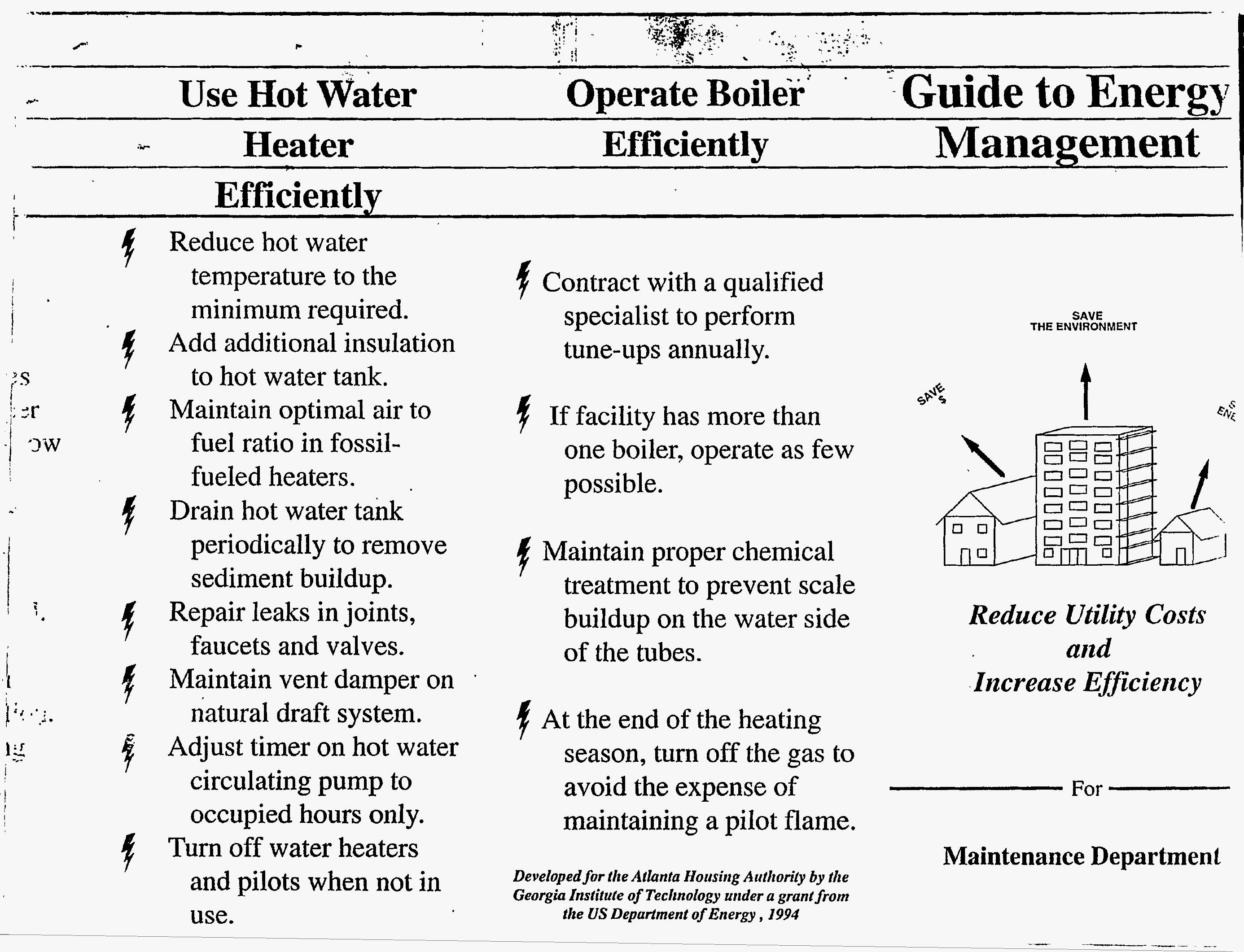




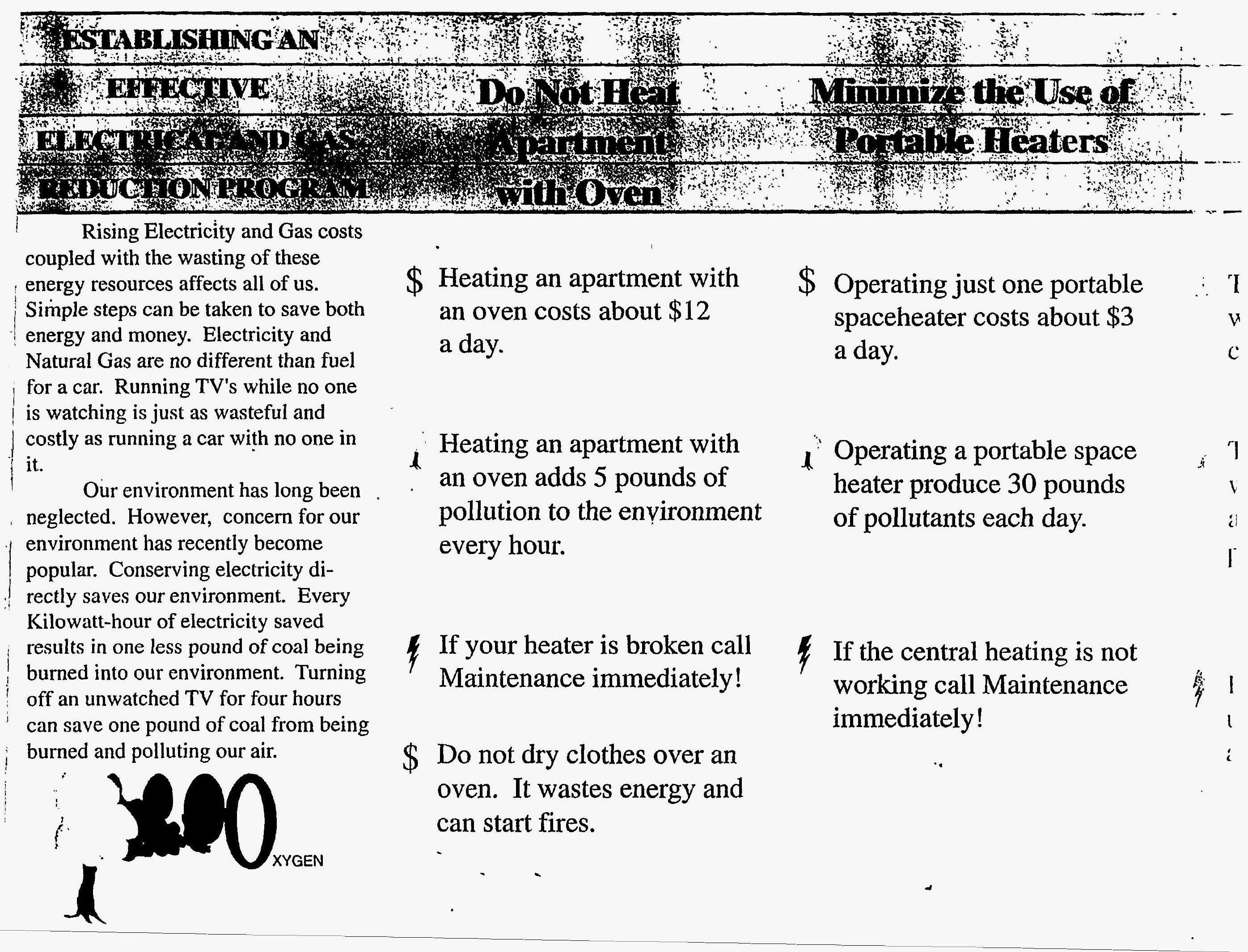




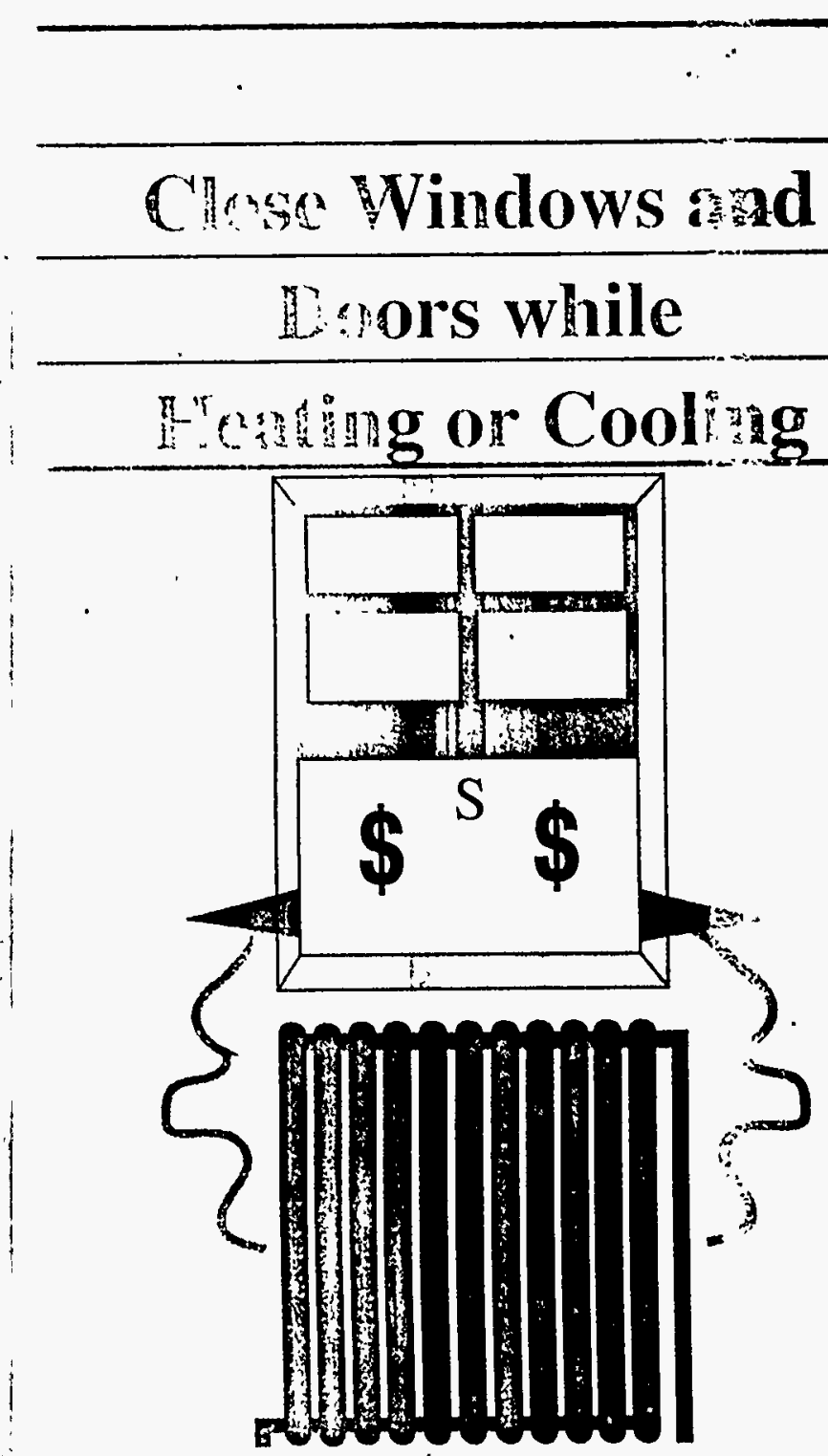

Keep windows and doe: closed while running a." conditioning or while heating.

\$ Shut off air conditionin $n_{i,}$ and

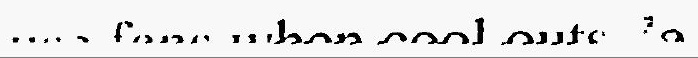
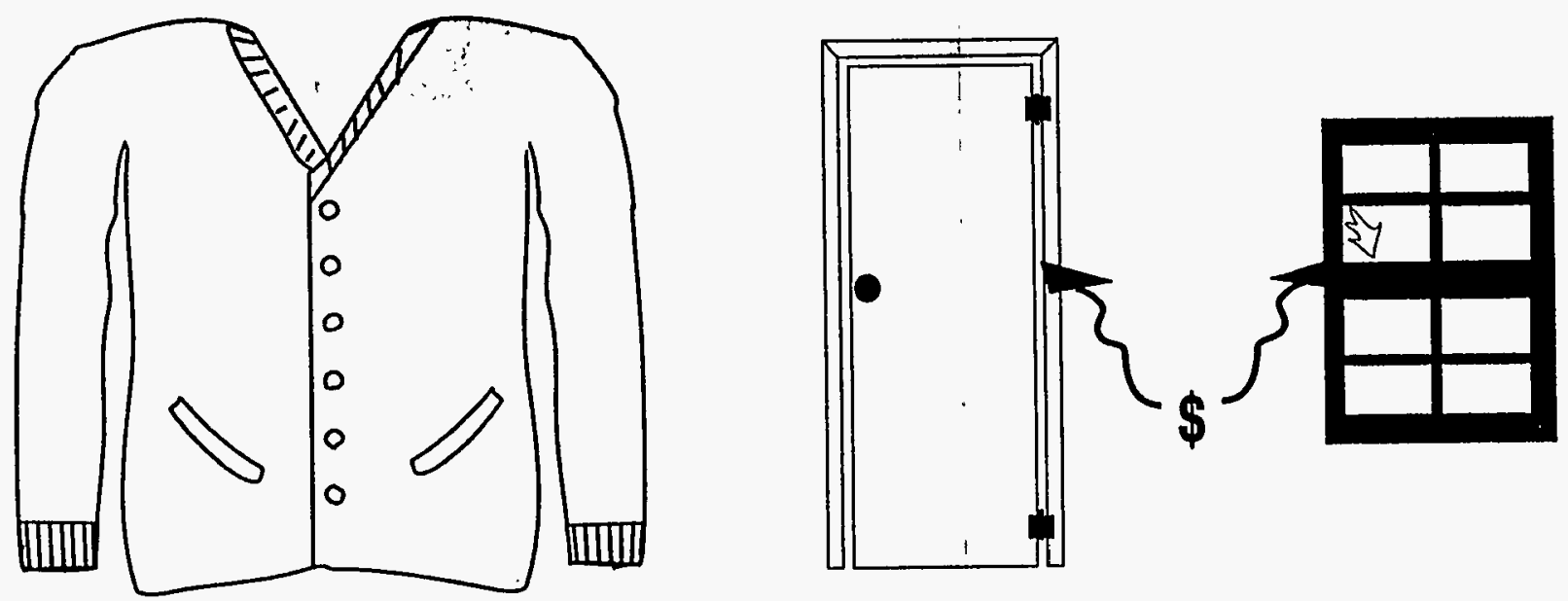

Dress warmly inside and lower heating temperature. Health benefits are also acheived by doing this.

\$ Add additional blankets to beds during heating season.

\section{Lower Heating}

Windows,

Doors and

Appliances 


\begin{tabular}{cccc}
\hline & $\cdot$ & Report Broken & Guide to \\
\hline and & Lower Heating & Windows, & Electricity and \\
\hline & - Temperature in & Doors and & Gas Savings \\
\hline ling & Winter & Appliances & \\
\hline
\end{tabular}

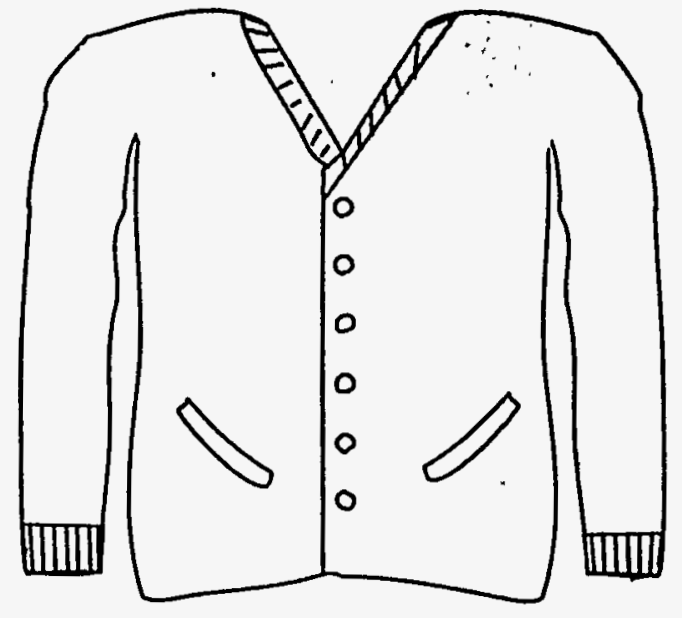

Dress warmly inside and lower heating temperature. Health benefits are also acheived by doing this.

\$ Add additional blankets to $\operatorname{lin}_{;} ;$and beds during heating season.

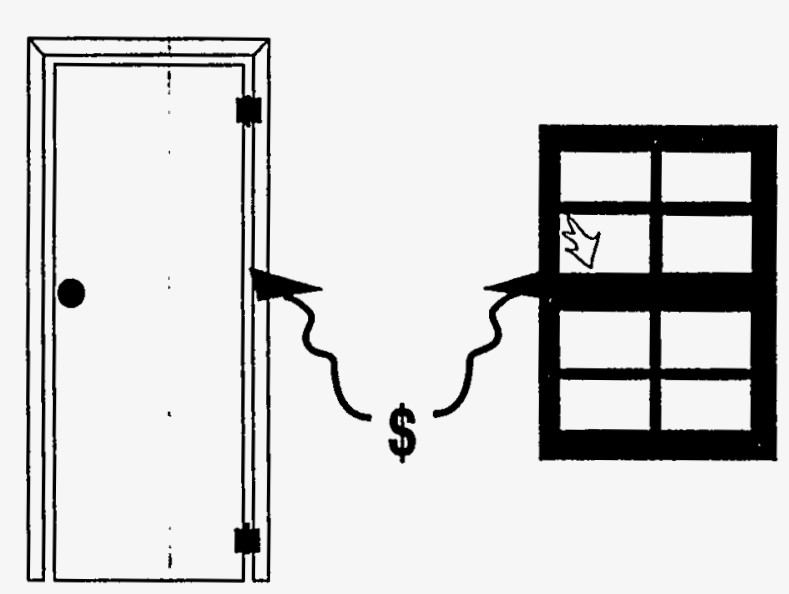

Immediately call the Maintenance Department to fix broken windows, doors and appliänces.

Developed for the Atlanta Housing Authority by the Georgia Institute of Technology under a grant from the US Department of Energy, 1994

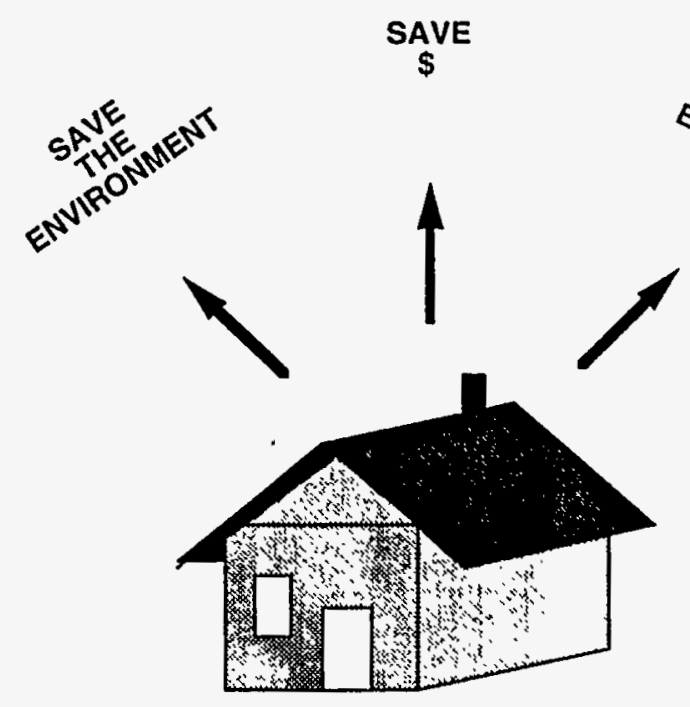

How to

Reduce Utility Costs and

Help the Environment For

Housing Developments its 


\section{ESTABLISHING AN}

EFFECTIVE

ELECTRICAL AND GAS REDUCTION PROGRAM

Rising Electricity and Gas costs oupled with the wasting of these enrgy resources affects all of us. Simple teps can be taken to save both energy nd money. Electricity and Natural Gas re no different than fuel for a car. zunning TV's while no one is watching sust as wasteful and costly as running car with no one in it.

Our environment has long been reglected. However, concern for our environment has recently become popuar. Conserving electricity directly Saves our environment. Every Kilowatt-hour of electricity saved results in ne less pound of coal being burned into ur environment. Turning off an unwatched TV for four hours can save one pound of coal from being burned and polluting our air.

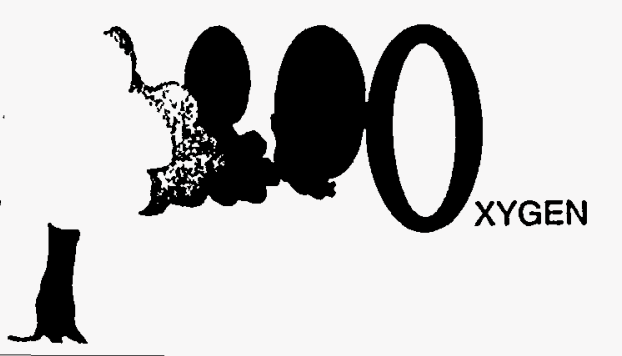

\$ Heating an apartment with an oven costs about $\$ 12$ a day.

1. Heating an apartment with an oven produces about 5 pounds of pollutants per hour.

If your heater is broken call Maintenance immediately!

\$ Do not dry clothes over an oven. It wastes energy and can start fires.

\section{Minimize the Use of}

\section{Portable Heaters}

\$ Operating just one portable spaceheater costs about $\$ 3$ a day.

Operating a portable space heater produces about 30 pounds of pollutants per day.

4 If the central heating is not working call Maintanence immediately! 


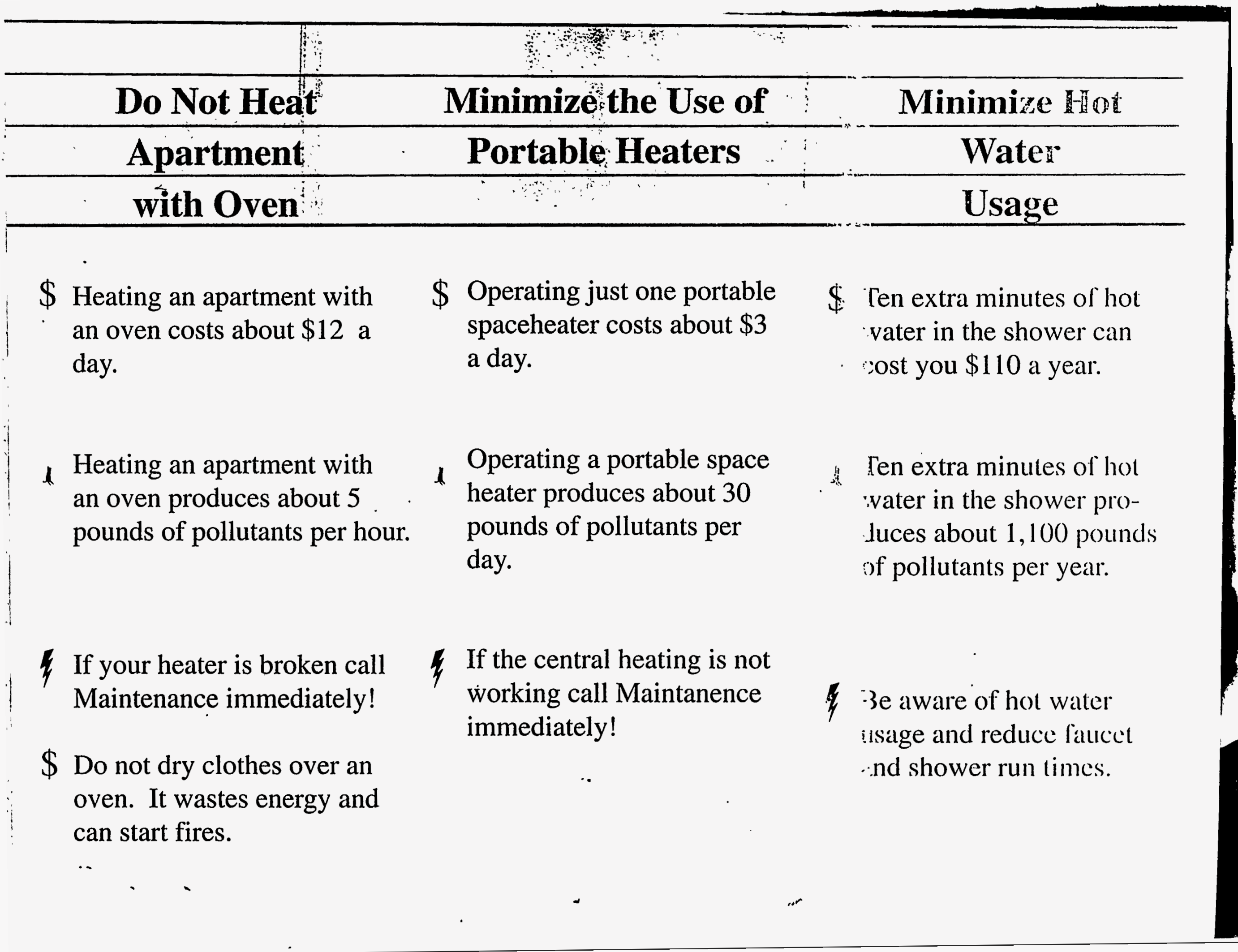




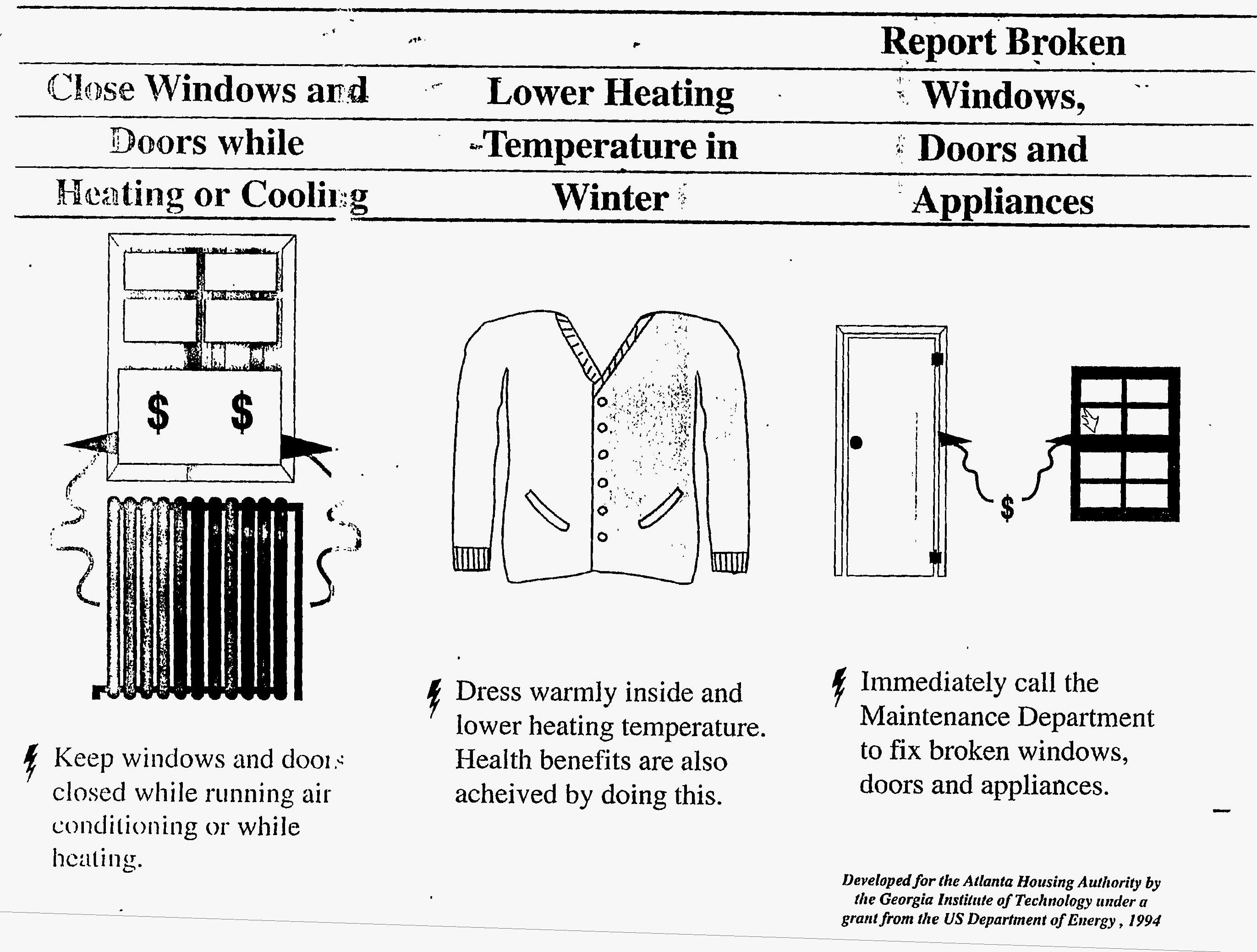




\begin{tabular}{|c|c|c|c|}
\hline . & & Report Broken & Guide to \\
\hline d & Lower Heating & Windows, & Electricity and \\
\hline & -Temperature in & Doors and & Gas Savings \\
\hline g & Winter & Appliances & \\
\hline
\end{tabular}

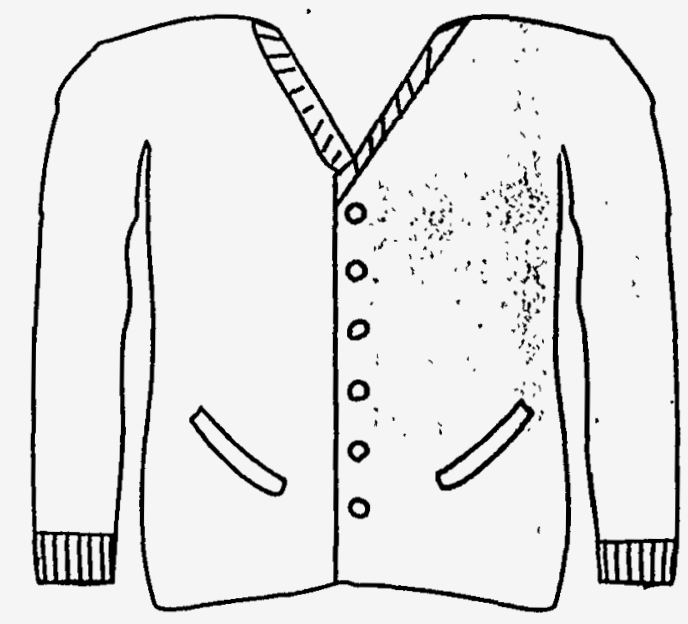

Dress warmly inside and lower heating temperature. Health benefits are also acheived by doing this.

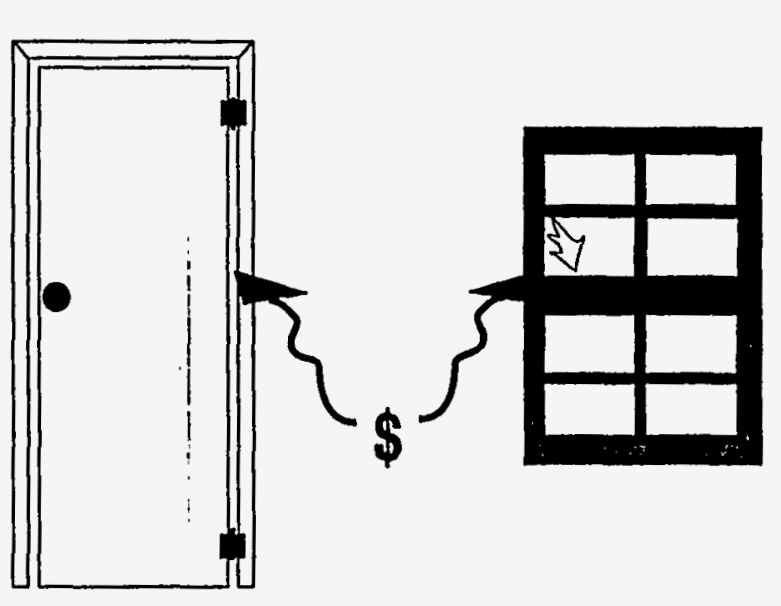

Immediately call the Maintenance Department to fix broken windows, doors and appliances. grant from the US Department of Energy , 1994

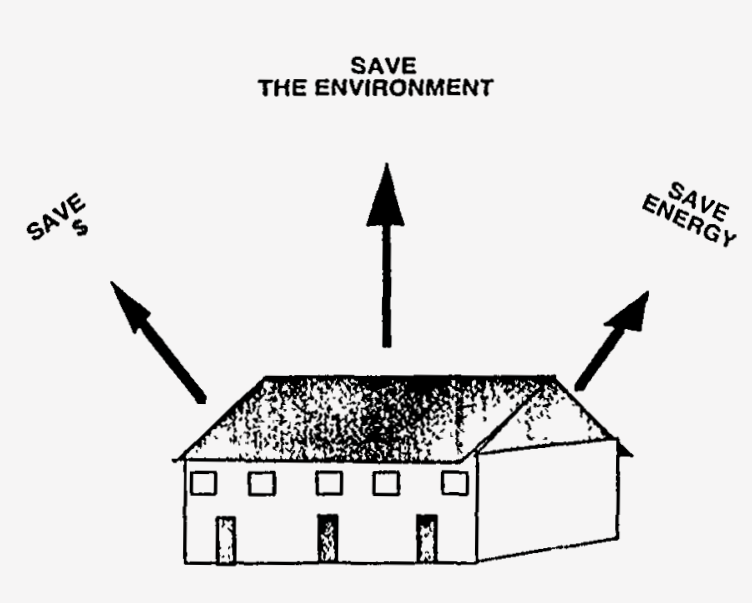

\section{How to}

Reduce Your Utility Costs and

Help the Environment

For

Low Rise Developments 
Rising Electricity and Gas costs coupled with the wasting of these energy sources affects all of us. Simple steps can be taken to save both energy and money. Electricity and Natural Gas are no different than fuel for a car. Running TV's while no one is watching is just as wasteful and costly as running a car with no one in it.

Our environment has long been neglected. However, concern for our environment has recently become popular. Conserving electricity directly saves our environment. Every Kilowatt-hour of electricity saved results in one less pound of coal being burned into our environment. Turning off an unwatched TV for four hours can save one pound of coal from being burned and polluting our air.

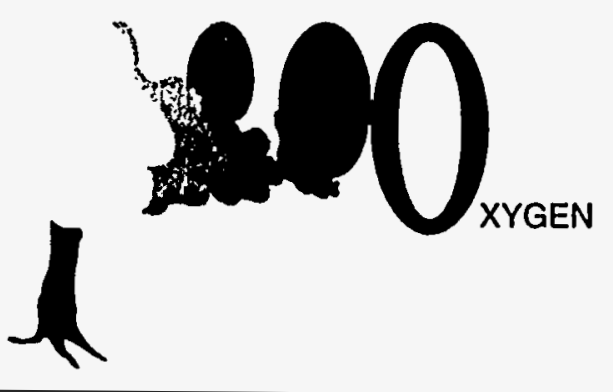

$\$$ Heating an apartment with an oven costs about $\$ 12$ a day.

1 Heating an apartment with an oven produces about 5 pounds of pollutants per hour.

If your heater is broken call Maintenance immediately!

Do not dry clothes over an oven. It wastes energy and can start fires.
$\$$ Operating just one portable spaceheater costs about $\$ 3$ a day.

1 Operating a portable space heater produces about 30 pounds of pollutants per day.

If the central heating is not working call Maintenance immediately! 
$\$$ Heating an apartment with an oven costs about $\$ 12$ a day.

1. Heating an apartment with an oven produces about 5 pounds of pollutants per hour.

If your heater is broken call Maintenance immediately!

Do not dry clothes over an oven. It wastes energy and can start fires.
$\$$ Operating just one portable spaceheater costs about $\$ 3$ a day.

Operating a portable space heater produces about 30 pounds of pollutants per day.

If the central heating is not working call Maintenance immediately!
$\$$ Ten extra minutes of hot water in the shower can cost you $\$ 110$ a year.

1 Ten extra minutes of hot water in the shower produces about 1,100 pounds of pollutants per year.

4 Be aware of hot water "ssage and reduce faucet ind shower run times. 
$\therefore$

\section{Report Broken}

Close Windows an:- Lower Heating Windows,

Cours while

Temperature in

Doors and

Feating or Coolin:

Winter

Appliances

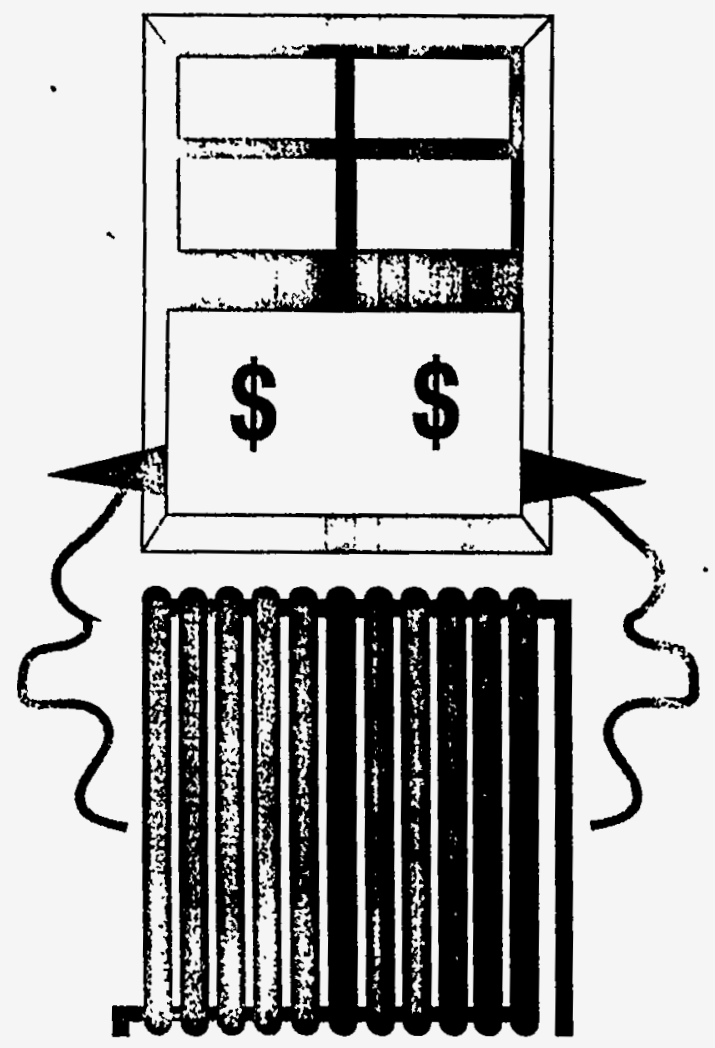

Keep windows and door: closed while running air conditioning or while heating.

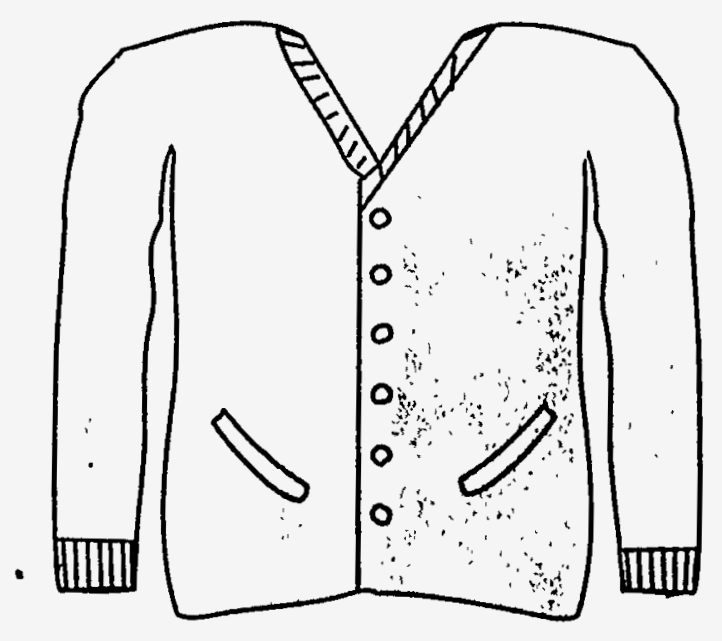

Dress warmly inside and lower heating temperature. Health benefits will also result from doing this.

4 Add additional blankets to beds and lower heating temperature..

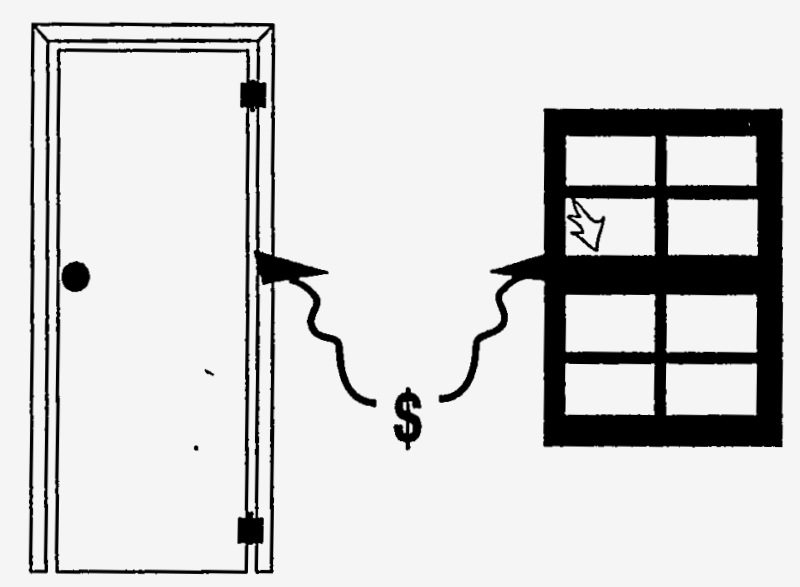

Immediately call the Maintenance Department to fix broken windows, doors and appliances.

Developed for the Atlanta Housing Authority by the Georgia Institute of Technology under a grant from the US Department of Energy, 1994 


\section{Temperature in} Winter

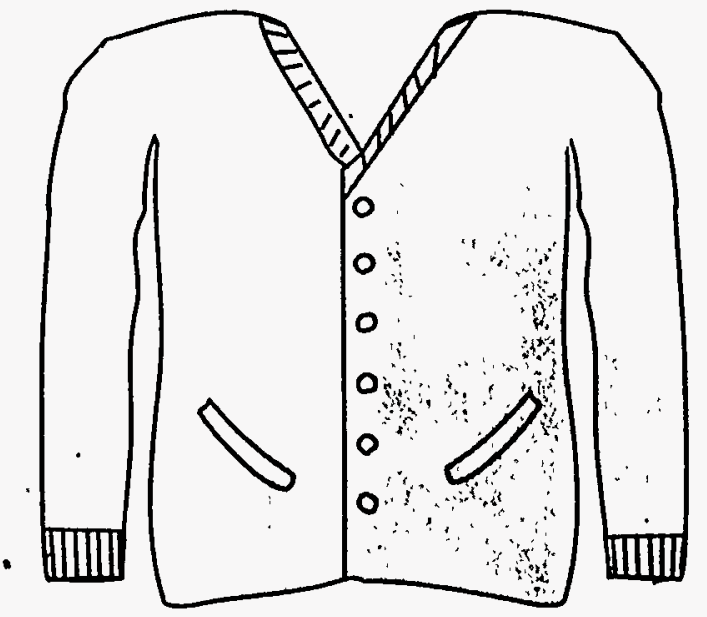

Dress warmly inside and lower heating temperature. Health benefits will also result from doing this.

Add additional blankets to beds and lower heating temperature..
Doors and Gas Savings Appliances
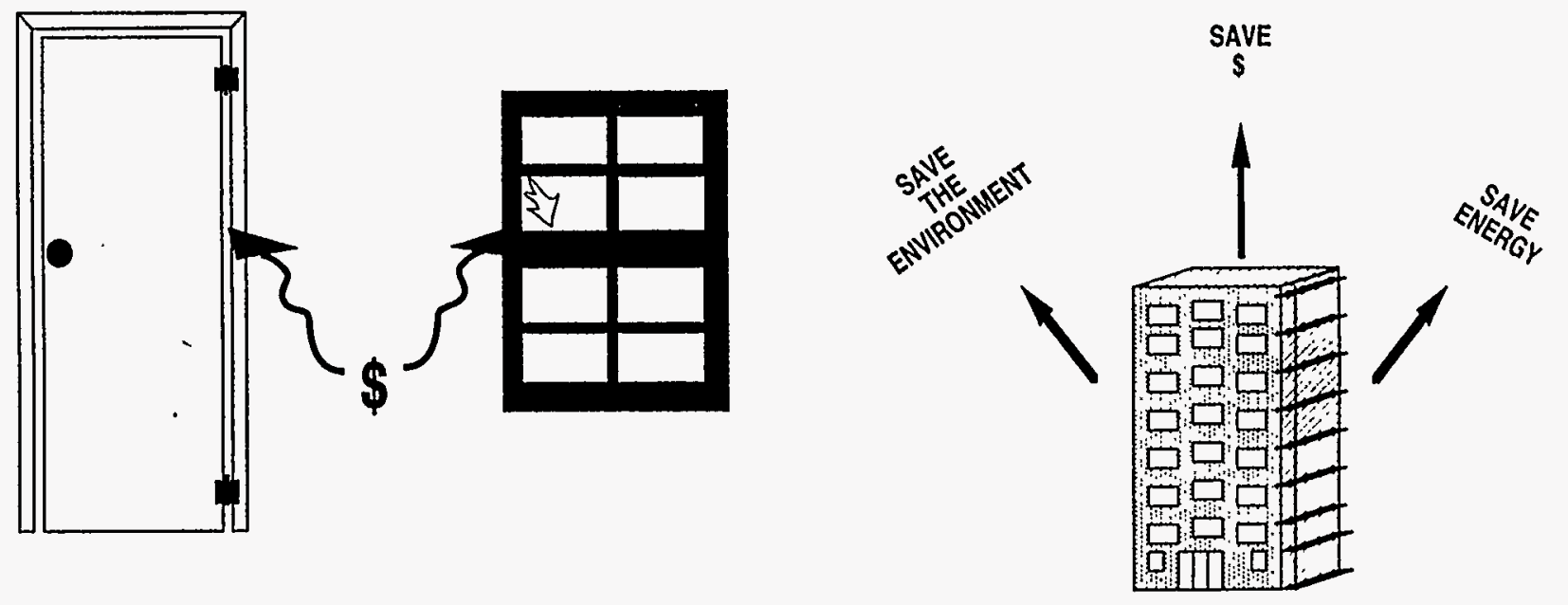

Immediately call the Maintenance Department to fix broken windows, doors and appliances.

How to

Reduce Utility Costs and

Help the Environment

For

High Rise Developments 